\title{
Additive Main Effects and Multiplicative Interaction and Other Stability Analyses of Tef [Eragrostis tef (Zucc.)Trotter] Grain Yield
}

\author{
Alemayehu Balcha \\ South Agricultural Research Institute, Hawassa Agricultural Research Centre, Hawassa, Ethiopia \\ Email: albalcha@yahoo.com
}

How to cite this paper: Balcha, A. (2020) Additive Main Effects and Multiplicative Interaction and Other Stability Analyses of Tef [Eragrostis tef (Zucc.)Trotter] Grain Yield. American Journal of Plant Sciences, 11, 793-802.

https://doi.org/10.4236/ajps.2020.116056

Received: May 11, 2019

Accepted: June 19, 2020

Published: June 22, 2020

Copyright $\odot 2020$ by author(s) and Scientific Research Publishing Inc. This work is licensed under the Creative Commons Attribution International License (CC BY 4.0).

http://creativecommons.org/licenses/by/4.0/ (c) (i) Open Access

\begin{abstract}
Tef [Eragrostis tef (Zucc.)Trotter]) is one of the most important cereal crops grown in Ethiopia. Tef production has been partly constrained by low yield and less stability of the genotypes under cultivation. Field experiments were carried out in Halaba, Loka Abaya, Bensa and Areka, South Ethiopia, from August to November, during 2016 and 2017 main cropping seasons, in order to estimate yield stability and the association between AMMI analysis and other stability parameters. Experiments were laid out in randomized complete block design with three replications using fourteen improved tef genotypes. Mean yield for Halaba, Loka Abaya2016, Loka Abaya2017, Bensa, Areka2016 and Areka2017 was 0.99, 0.45, 0.48, 1.50, 1.62 and 0.77 tons/ha, respectively. Genotypes Amarach, Boset, Simada, and Tseday exhibited high mean yield of 1.09, 1.10, 1.07 and 1.07 tons/ha, respectively. AMMI stability value (ASV) ranged from 0.17 (genotype Lakech) to 1.40 (Amarach); yield stability index (YSI) from 7 (Lakech) to 25 (Quncho); and superiority measure $\left(P_{i}\right)$ from 0.015 (Boset) to 0.145 (Dega Tef). Rank correlation of yield with $P_{i}(r=$ $0.97, p<0.01)$, ASV with $W_{i}$ and $\delta_{i}^{2} \quad(r=0.85, p<0.01)$ and that between $W_{i}$ and $\delta_{i}^{2} \quad(r=1.00, p<0.01)$ was high. Rank correlation of YSI with yield $(r=$ $0.57, p<0.05)$, ASV $(r=0.75, p<0.01), P_{i}(r=0.68, p<0.01)$ and $W_{i}$ and $\delta_{i}^{2}$ $(r=0.67, p<0.01)$ was positive. The present study showed that genotypes Etsub, Simada and Tseday would be recommended for high yield and wide adaptation, and ASV would be used alone or jointly with YSI, $W_{i}$ and $\delta_{i}^{2}$ for ranking of genotypes.
\end{abstract}

\section{Keywords}

AMMI Analysis, Stability, Rank Correlations, Grain Yield, Tef, Eragrostis tef 


\section{Introduction}

Tef [Eragrostis tef (Zucc.)Trotter]) is one of the most important cereal crops grown in Ethiopia. It occupies about three million ha of land $(29.51 \%$ of area allocated to cereals) with the total annual production of about five million tons of grain (19.78\% of cereals production) per year. In South region alone, tef occupies about 246,099 ha of land $(27.80 \%$ of area allocated to cereals) producing about 341,255 tons of grain ( $15.97 \%$ of cereal production) per year. The low national (1.66 tons/ha) as well as regional (1.39 tons/ha) yield of tef [1] could be partly attributed to low yield and less stability of genotypes under cultivation.

Yield is a complex quantitative trait often affected by genotype, environment and genotype by environment interaction (GEI). The differential responses of genotypes across environments occur because of differences in expression of different sets or the same set of genes in different environments [2]. GEI complicates selection of any superior genotype across environments because it reduces the association between phenotypic and genotypic values [3].

Yield stability usually refers to a genotype's ability to produce high or low yield consistently across a wide range of environments [4]. Among several statistical techniques used to study yield stability, ecovalence [5] and stability variance [6] refer to the contribution of a genotype to the GEI sum of squares so that a genotype with minimum value is considered to be most stable. On the other hand, a genotype having minimum superiority measure $\left(P_{i}\right)$, defined as the mean square of distance between a genotype and the maximum responses, is considered the most desirable because it has less distance from the maximum responses [7].

The ordinary analysis of variance partitions the treatment sum of squares into additive main effects of genotypes and environments and non-additive genotype by environment interaction effect [8]. Additive main effects and multiplicative interaction (AMMI) model on the other hand combines analysis of variance for additive effects and principal component analysis for multiplicative, non-additive effect. It discards not only the residual or noise variation from the GEI but also generates principal component axes which retain the variation in GEI in decreasing pattern so that the first axis captures most of the variation. In addition, AMMI biplot provides graphical presentation of multi-environment data and identification of genotypes with wide and specific adaptations [9] [10] [11] [12].

Selection of stable genotypes which react less with the changes in environments requires the use of more than one stability measures because a single method may not adequately explain the performance of genotypes across a range of environments [13]. The present study therefore was carried out in order to estimate yield stability and the association between AMMI analysis and other stability parameters for tef.

\section{Materials and Methods}

Field experiments were carried out on-station in Halaba, Loka Abaya, Bensa and Areka, South Ethiopia, from August to November, during 2016 main cropping season. The experiments in Loka Abaya and Areka were also repeated during 
2017 main cropping season. Halaba is located at $07^{\circ} 18^{\prime} 45^{\prime \prime} \mathrm{N}, 37^{\circ} 06^{\prime} 49^{\prime \prime} \mathrm{E}$ and $1765 \mathrm{~m}$ above sea level with annual average rainfall of about $857 \mathrm{~mm}$ and temperature of $22.22^{\circ} \mathrm{C}$. Loka Abaya is located at $06^{\circ} 29^{\prime} 60^{\prime \prime} \mathrm{N}, 37^{\circ} 52^{\prime} 60^{\prime \prime} \mathrm{E}$ and 1835 $\mathrm{m}$ above sea level with annual average rainfall and temperature of about $938 \mathrm{~mm}$ and $20.9^{\circ} \mathrm{C}$, respectively. Bensa is located at $06^{\circ} 48^{\prime} 61^{\prime \prime} \mathrm{N}, 38^{\circ} 77^{\prime} 66^{\prime \prime} \mathrm{E}$ and $1992 \mathrm{~m}$ above sea level. It has annual average rainfall and temperature of about $1096 \mathrm{~mm}$ and $18.85^{\circ} \mathrm{C}$, respectively. Areka is located at $07^{\circ} 42^{\prime} 24^{\prime \prime} \mathrm{N}, 37^{\circ} 41^{\prime} 10^{\prime \prime} \mathrm{E}$ and $1830 \mathrm{~m}$ above sea level having annual average rainfall of about $1520 \mathrm{~mm}$ and temperature of $20.0^{\circ} \mathrm{C}$. The soils of Halaba, Loka Abaya, Bensa and Areka are loam, silty clay, clay, and clay loam, respectively.

Fourteen improved tef genotypes obtained from Debre-Zeit Agricultural Research Centre, Debre Zeit, Ethiopia, were planted late August in Halaba (2016) and Areka (2016 and 2017), and early September in Bensa (2016) and Loka Abaya (2016 and 2017), during main cropping seasons, in randomized complete block design with three replications. Each plot consisted of six rows of $2.5 \mathrm{~m}$ long with $20 \mathrm{~cm}$ between rows, and $1.20 \mathrm{~m}$ between replications, and $80 \mathrm{~cm}$ between plots. The seed was drilled using $15 \mathrm{~kg} / \mathrm{ha}$ seed rate. Plots received 65 $\mathrm{kg} / \mathrm{ha} \mathrm{N}$ in the form of urea and NPS, and $38 \mathrm{~kg} / \mathrm{ha} \mathrm{P}_{2} \mathrm{O}_{5}$ in the form of NPS applied at planting. Weeds were controlled with hand weeding throughout the experiment period.

Stability parameters for yield (tons/ha) were estimated with $X_{i j}$ is the yield of ith genotype in the jth environment, $n$ is the number of genotypes, $m$ is the number of environments, $X_{i}$ is the mean yield of ith genotype across environments, $X_{j}$ is the mean yield of jth environment and $X$ is the grand mean.

Ecovalence $\left(W_{i}\right)[5]$ :

$$
W_{i}=\sum\left(X_{i j}-X_{i .}-X_{. j}+X_{. .}\right)^{2}
$$

Stability variance $\left(\delta_{i}^{2}\right)[6]$ :

$$
\begin{aligned}
\delta_{i}^{2}= & \frac{1}{(n-1)(n-2)(m-1)}\left[n(n-1) \sum\left(X_{i j}-X_{i .}-X_{. j}+X_{. .}\right)^{2}\right. \\
& \left.-\sum_{i} \sum_{j}\left(X_{i j}-X_{i .}-X_{. j}+X_{. .}\right)^{2}\right]
\end{aligned}
$$

Superiority measure $\left(P_{i}\right)[7]$ :

$$
P_{i}=\left[n\left(X_{i .}-M_{.}\right)^{2}+\sum\left(X_{i j}-X_{i .}-M_{j}+M_{.}\right)^{2}\right] / 2 n
$$

where $M_{j}$ is the maximum response in environment $j$ and $M$. is the average maximum response across environments. The first term of this equation represents the genotype sum of squares and the second term represents the GEI sum of squares. Genotypes with minimum $P_{i}$ values are considered more stable because they have less distance from the maximum responses.

AMMI model was based on Zobel et al. [9]:

$$
X_{i j}=\mu+g_{i}+e_{j}+\sum_{k=1}^{n} \lambda_{k} \alpha_{i k} \gamma_{j k}+e_{i j}
$$

where $X_{i j}$ is the yield of the $i$ th genotype in the th environment, $\mu$ is the grand mean, $g_{i}$ is the genotype mean deviation, $e_{j}$ is the environment mean deviation, 
$\lambda_{k}$ is the eigenvalue of the PCA axis, $k, \alpha_{i k}$ and $\gamma_{j k}$ are the principal component scores for PCA axis $k$ of the ith genotype and the th environment, respectively, $n$ is the number PCA axes retained in the model and $e_{i j}$ is the residual.

Since IPCA1 contributes more to the GEI sum of squares, AMMI stability value (ASV) for each genotype and environment was calculated to compensate for the relative contribution of IPCA1 and IPCA2 to the total GEI [14] as:

$$
\mathrm{ASV}=\sqrt{[\text { IPCA1ss/IPCA2ss(IPCA1score })]^{2}+(\text { IPCA2score })^{2}}
$$

where IPCA1ss and IPCA2ss are sum of squares of IPCA1 and IPCA2, respectively. The small ASV score indicates a more stable genotype as well as less interactive environment.

Analysis of variance, ecovalence, stability variance, superiority measure and rank correlation were analyzed using SAS software version 9.0 [15], and AMMI analysis was done using Genstat version 18.1 [16].

\section{Results}

AMMI analysis (Table 1) showed that the effects of genotype, environment and genotype by environment interaction (GEI) were highly significant $(p<0.01)$, and their respective contribution to the treatment sum of squares was $4.37 \%$, $87.30 \%$ and $8.33 \%$. The IPCA1 (56.40\%) and IPCA2 (21.00\%) together contributed $77.40 \%$ of GEI sum of squares.

Yield (tons/ha) ranged from 0.72 (genotype Dega Tef) to 1.22 (Kora) in E1; 0.23 (Quncho) to 0.62 (Amarach) in E2; 0.27 (Dega Tef) to 0.78 (Simada) in E3; 1.02 (Quncho) to 2.01 (Amarach) in E4; 1.11 (Dega Tef) to 1.86 (Genete) in E5; and 0.50 (Dega Tef) to 1.01 (Kora) in E6. Mean yield for E1, E2, E3, E4, E5 and E6 was $0.99,0.45,0.48,1.50,1.62$ and 0.77 tons/ha, respectively. Environments E4 and E6 had high IPCA1 score of -0.74 and 0.42 , respectively, whereas the IPCA2 score was high for E1 (-0.42) and E5 (0.56). ASV was high for E4 (1.99), E5 (1.05) and E6 (1.15) and it was low for E2 (0.33) and E3 (0.53) (Table 2).

Mean yield (tons/ha) ranged from 0.74 (genotype Dega Tef) to 1.10 (Boset). Genotypes Amarach (1.09), Simada (1.07) and Tseday (1.07) also exhibited the next high yield. Genotypes Amarach (-0.52), Boset (-0.34), Kora (0.33) and Quncho (0.51) had high scores of IPCA1 whereas the IPCA2 scores were high for Kora (-0.35) and Simada (0.34). ASV was low for Key Tena (0.25), Lakech (0.17), and Zobel (0.25), and it was high for Amarach (1.40) and Quncho (1.38). Yield stability index (YSI) was low for Etsub (9), Lakech (7) and Tseday (9). The values of $W_{i}$ and $\delta_{i}^{2}$ were high for Amarach, Boset, Kora and Quncho, and they were low for Lakech, Mechare and Tseday. The Pi value was high for Dega Tef, Key Tena and Quncho whereas it was low for Boset and Tseday (Table 3).

The rank correlation of yield with $P_{i}(r=0.97, p<0.01)$, ASV with $W_{i}$ and $\delta_{i}^{2}$ $(r=0.85, p<0.01)$ and that between $W_{i}$ and $\delta_{i}^{2}(r=1.00, p<0.01)$ was high. The rank correlation of yield with YSI $(r=0.57, p<0.05)$, ASV $(r=0.75, p<$ $0.01), \mathrm{Pi}(r=0.68, p<0.01)$, and $W_{i}$ and $\delta_{i}^{2} \quad(r=0.67, p<0.01)$ was positive (Table 4). 
Table 1. AMMI analysis of yield(tons/ha) for fourteen tef genotypes grown in six environments.

\begin{tabular}{cccccc}
\hline Source of variation & d.f & Sum of squares (SS) & Mean squares & \% Treatment SS & $\% \mathrm{GxE}$ \\
\hline Total & 251 & 66.78 & 0.266 & & \\
Replications/E & 12 & 0.89 & $0.074^{\star}$ & & \\
Treatments & 83 & 60.01 & $0.723^{* *}$ & & \\
Genotypes(G) & 13 & 2.62 & $0.202^{* *}$ & 4.37 & \\
Environments(E) & 5 & 52.39 & $10.478^{* *}$ & 87.30 & \\
Gx E & 65 & 5.00 & $0.077^{* *}$ & 8.33 & \\
IPCA1 & 17 & 2.82 & $0.166^{* *}$ & & 56.40 \\
IPCA2 & 15 & 1.05 & $0.070^{*}$ & & 21.00 \\
IPCA3 & 13 & 0.70 & $0.054 \mathrm{~ns}$ & & 14.00 \\
IPCA4 & 11 & 0.25 & $0.023 \mathrm{~ns}$ & & 5.00 \\
Residuals & 9 & 0.18 & $0.020 \mathrm{~ns}$ & & 3.60 \\
Error & 156 & 5.88 & 0.038 & & \\
\hline
\end{tabular}

${ }^{*},{ }^{*}$ significant at $5 \%$ and $1 \%$ probability level, respectively, ns = not-significant.

Table 2. Yield (tons/ha) of fourteen tef genotypes grown in six environments.

\begin{tabular}{|c|c|c|c|c|c|c|}
\hline Genotypes & E1 & E2 & E3 & $\mathrm{E} 4$ & E5 & E6 \\
\hline Amarach & 0.91 & 0.62 & 0.71 & 2.01 & 1.56 & 0.71 \\
\hline Boset & 1.06 & 0.47 & 0.69 & 1.94 & 1.79 & 0.67 \\
\hline Dega Tef & 0.72 & 0.43 & 0.27 & 1.40 & 1.11 & 0.50 \\
\hline Etsub & 1.19 & 0.39 & 0.51 & 1.71 & 1.57 & 0.85 \\
\hline Gemechis & 0.88 & 0.55 & 0.32 & 1.40 & 1.71 & 0.87 \\
\hline Genete & 0.98 & 0.50 & 0.46 & 1.33 & 1.86 & 0.79 \\
\hline Key Tena & 0.88 & 0.49 & 0.43 & 1.32 & 1.28 & 0.68 \\
\hline Kora & 1.22 & 0.35 & 0.32 & 1.31 & 1.53 & 1.01 \\
\hline Lakech & 1.08 & 0.48 & 0.52 & 1.52 & 1.80 & 0.69 \\
\hline Mechare & 1.02 & 0.38 & 0.41 & 1.22 & 1.55 & 0.72 \\
\hline Quncho & 0.95 & 0.23 & 0.43 & 1.02 & 1.76 & 0.91 \\
\hline Simada & 0.86 & 0.55 & 0.78 & 1.64 & 1.80 & 0.81 \\
\hline Tseday & 1.01 & 0.57 & 0.56 & 1.71 & 1.73 & 0.85 \\
\hline Zobel & 1.16 & 0.32 & 0.33 & 1.49 & 1.56 & 0.71 \\
\hline Mean & 0.99 & 0.45 & 0.48 & 1.50 & 1.62 & 0.77 \\
\hline F-ratio & * & * & $* *$ & * & * & * \\
\hline $\mathrm{CV}, \%$ & 15.59 & 26.51 & 27.40 & 19.71 & 15.59 & 17.95 \\
\hline $\mathrm{LSD}_{0.05}$ & 0.26 & 0.20 & 0.22 & 0.50 & 0.42 & 0.23 \\
\hline IPCA1 & 0.29 & -0.12 & -0.18 & -0.74 & 0.33 & 0.42 \\
\hline IPCA2 & -0.42 & -0.09 & 0.21 & -0.07 & 0.56 & -0.20 \\
\hline ASV & 0.89 & 0.33 & 0.53 & 1.99 & 1.05 & 1.15 \\
\hline
\end{tabular}


Table 3. Mean yield (tons/ha) and stability parameters for fourteen tef genotypes grown in six environments.

\begin{tabular}{cccccccccc}
\hline Code & Genotypes & Yield & IPCA1 & IPCA2 & ASV & YSI & $W_{i}$ & $\delta_{i}^{2}$ & $P_{i}$ \\
\hline 1 & Amarach & 1.09 & -0.52 & 0.02 & 1.40 & 16 & $0.270^{* *}$ & $0.061^{* *}$ & 0.023 \\
2 & Boset & 1.10 & -0.34 & 0.18 & 0.94 & 12 & $0.173^{*}$ & $0.038^{*}$ & 0.015 \\
3 & Dega Tef & 0.74 & -0.25 & -0.26 & 0.73 & 24 & 0.139 & $0.030^{*}$ & $0.145^{*}$ \\
4 & Etsub & 1.04 & -0.08 & -0.22 & 0.30 & 9 & 0.067 & 0.014 & 0.027 \\
5 & Gemechis & 0.96 & 0.14 & 0.08 & 0.38 & 14 & 0.077 & 0.016 & 0.062 \\
6 & Genete & 0.99 & 0.22 & 0.24 & 0.63 & 16 & 0.091 & 0.019 & 0.057 \\
7 & Key Tena & 0.85 & -0.05 & -0.21 & 0.25 & 16 & 0.081 & 0.017 & $0.098^{*}$ \\
8 & Kora & 0.96 & 0.33 & -0.35 & 0.96 & 21 & $0.188^{*}$ & $0.042^{* *}$ & 0.074 \\
9 & Lakech & 1.02 & 0.03 & 0.15 & 0.17 & 7 & 0.038 & 0.007 & 0.038 \\
10 & Mechare & 0.88 & 0.20 & -0.04 & 0.53 & 19 & 0.053 & 0.010 & 0.087 \\
11 & Quncho & 0.88 & 0.51 & 0.20 & 1.38 & 25 & $0.283^{* *}$ & $0.064^{* *}$ & $0.112^{*}$ \\
12 & Simada & 1.07 & -0.14 & 0.34 & 0.50 & 10 & 0.106 & 0.023 & 0.026 \\
13 & Tseday & 1.07 & -0.11 & 0.06 & 0.31 & 9 & 0.020 & 0.003 & 0.019 \\
14 & Zobel & 0.93 & 0.06 & -0.18 & 0.25 & 12 & 0.065 & 0.013 & 0.062 \\
& Mean & 0.97 & & & & & & & \\
\hline
\end{tabular}

*, ** significant at $5 \%$ and $1 \%$ probability level, respectively; $5 \%$ cutoff point for $\mathrm{Pi}$ is 0.082 .

Table 4. Rank correlations among yield and five stability parameters for fourteen tef genotypes grown in six environments.

\begin{tabular}{cccccc}
\hline Traits & ASV & YSI & $W_{i}$ & $\delta_{i}^{2}$ & $P_{i}$ \\
\hline Yield & $-0.09 \mathrm{~ns}$ & $0.57^{*}$ & $0.01 \mathrm{~ns}$ & $0.01 \mathrm{~ns}$ & $0.97^{* *}$ \\
ASV & & $0.75^{* *}$ & $0.85^{* *}$ & $0.85^{* *}$ & $0.07 \mathrm{~ns}$ \\
YSI & & & $0.67^{* *}$ & $0.67^{* *}$ & $0.68^{* *}$ \\
$W_{i}$ & & & & $1.00^{* *}$ & $0.17 \mathrm{~ns}$ \\
$\delta_{i}^{2}$ & & & & $0.17 \mathrm{~ns}$ \\
\hline
\end{tabular}

${ }^{*}{ }^{* *}$ significant at $5 \%$ and $1 \%$ probability level, respectively, ns = not-significant.

\section{Discussion}

In the present study, the greater contribution of environment (87.30\%) relative to genotype (4.37\%) and GEI (8.33\%) to the treatment sum of squares suggests the greater diversity in test environments. It has also been reported that environment usually explains $80 \%$ or more of the total variation in multi environment yield trials [17] [18]. The significant GEI would also suggest the existence of considerable differences among genotypes in their responses to varying environments.

Analysis of variance was verified by using sums of squares (SS) for genotypes (G), GEI signal (GEIS) and GEI noise (GEIN) [10] [19]. The GEIN is obtained 
by multiplying mean squares of error by the GEI degrees of freedom and then GEIS is obtained by subtracting GEIN from GEI sum of squares. Accordingly, 0.038 (error mean square) $\times 65$ (GEI degrees of freedom $)=2.47$ noise sum of squares $(49.40 \%$ of GEI) and $5.00-2.47=2.53$ signal sum of squares $(50.60 \%)$. This showed that the AMMI analysis was appropriate because it fulfilled the minimum requirement that $G E I S$ must be as large as $G$ for the dataset [19]. On the other hand, the low relevant variation ( $G$ plus $G E I S$ ) of $2.62+2.53=5.15$ or $8.58 \%$ of the treatment SS was in consistent with previous reports in other studies [10].

The IPCA 1 and IPCA 2 captured $77.40 \%$ of the GEI SS making them sufficient to explain the variability in GEI because they explained more than the minimum requirement of $70 \%$ of the total variation in GEI [12]. Moreover, nearly similar variation in yield explained by genotype (2.62) and IPCA1 (2.82) would suggest that both wide and specific adaptations are equally important because genotype and GEI effects determine wide and specific adaptations, respectively [10] [18].

The lack of rank correlation of $P_{i}$ with ASV, $W_{i}$ and $\delta_{i}^{2}$ would indicate the difference between $P_{i}$ and the later procedures in ranking genotypes as it was reported in previous studies [14]. Genotypes Boset (0.015) and Tseday (0.019) had low $P_{i}$ values and considered to have low deviation from the maximum response in an environment [7]. Moreover, nearly perfect rank correlation ( $r=$ $0.97, p<0.01)$ between yield and Pi suggests that selection for low $P_{i}$ would lead to genotypes performing close to maximum performance in each environment. However, $P_{i}$ is a measure of performance, rather than a stability measure because inherently high yielding genotypes would always be close to the maximum yielder over the respective environments and also the top yielding genotypes may differ from one environment to another [14].

Most genotypes except Amarach, Boset, Kora and Quncho were considered more stable for their low values in both $W_{i}(0.020-0.139)$ and $\delta_{i}^{2}(0.003-$ $0.023)$. Moreover, perfect rank correlation $(r=1.00, p<0.01)$ between $W_{i}$ and $\delta_{i}^{2}$ could be expected because $\delta_{i}^{2}$ is a linear combination of ecovalence $\left(W_{i}\right)$ [20]. The high rank correlation $(r=0.85, p<0.01)$ of ASV with $\delta_{i}^{2}$ and $W_{i}$ suggests that one or more of these methods would be used for ranking genotypes. However, ASV is more preferable because AMMI analysis recovers not only real pattern but also discards irrelevant noise from GEI [10] [21].

Selection process requires combining high yield and stability because a stable genotype is not necessarily high yielding. Yield stability index (YSI) was calculated as the sum of rank of mean yield and ASV by assigning a rank of 1 for the highest yield and for the lowest ASV value so that a genotype with the lowest YSI value was considered most stable [22]. Thus, genotypes Etsub, Lakech and Tseday were most desirable because they combined both high yield and stability. The substantial rank correlation of YSI with $W_{i}$ and $\delta_{i}^{2}(r=0.67, p<$ $0.01)$, and $P_{i}(r=0.68, p<0.01)$ suggests that YSI would be used alone or jointly with the later procedures for ranking of genotypes. Moreover, lack of rank correlation between yield and ASV suggests that simultaneous improve- 
ment in both yield and stability would be possible even though most high yielding genotypes are not always stable [22] [23]. This was observed for the high yielding genotype Amarach (1.09 tons/ha) which was not stable with regard to IPCA1, ASV, YSI, $W_{i}$ and $\delta_{i}^{2}$.

In AMMI1 biplot (Figure 1), ordinate shows interaction differences for genotypes and environments, and abscissa shows the main effects of genotypes and environments. It explained $96.37 \%$ of the treatment SS by capturing genotype SS of $2.62(4.37 \%)$, environment SS of $52.39(87.30 \%)$ and $2.82(4.70 \%)$ of IPCA1 leaving less than $4 \%$ SS of noise. Genotypes and environments with near zero IPCA1 scores are less interactive compared to those far from zero. Similarly, genotypes located at the right side of the vertical line (mean yield) have yields above mean yield and those at the left side of the vertical line have yields below mean yield [9]. Thus, Loka Abaya (E2 and E3) was less interactive and low yielding whereas environment E4 (Bensa), E5 (Areka2016) and genotypes G1 (Amarach) and G2 (Boset) were both high yielding and most interactive. Environment E6 (Areka2017), and genotypes G3 (Dega Tef) and G11 (Quncho) exhibited low yield and high interaction while G4 (Etsub), G12 (Simada) and G13 (Tseday) had high yield and more stable interaction.

Genotypes and environments with large IPCA1 scores of the same and different signs have positive and negative interactions, respectively [9]. Thus, genotypes G1 (Amarach) and G2 (Boset) were most adapted to Bensa (E4) and genotype G8 (Kora) was best adapted to Halaba (E1) and Areka (E5 and E6). Genotypes and environments that appear almost on a parallel line, relative to the ordinate, have similar mean yield and those that fall almost on a horizontal line

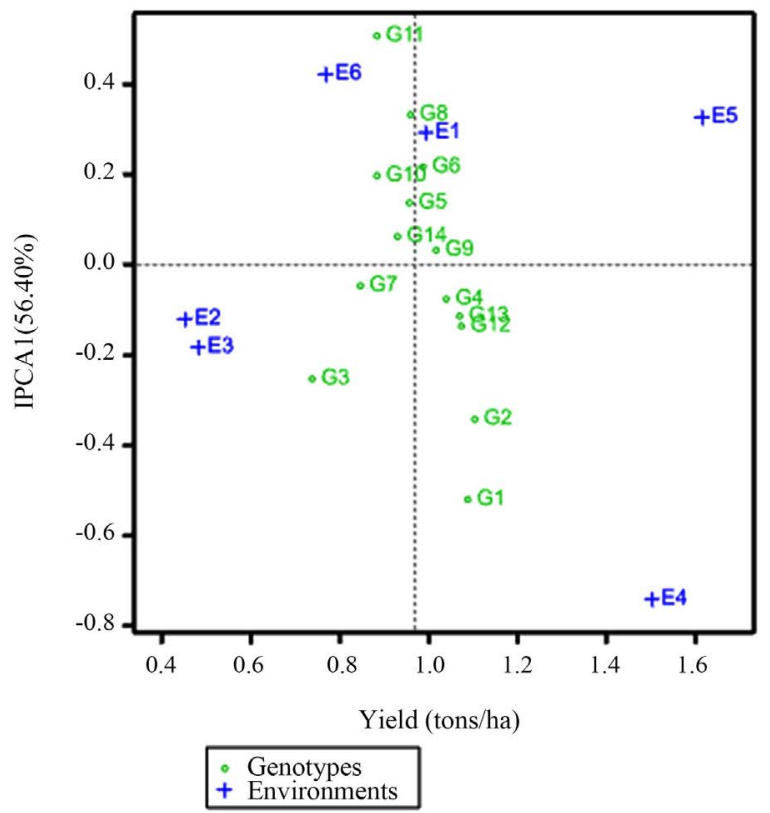

Figure 1. AMMI1 biplot for main effects and IPCA1 for yield of fourteen tef genotypes grown in six environments; refer to Table 2 for environments and Table 3 for genotypes designations. 
have similar interaction patterns [10]. Thus, environments E2 and E3 had similar yield and interaction patterns whereas E5 and E6 were differed in main effects but had similar interaction. Unlike Areka (E5 and E6), less variability from year to year in main effects and interactions in Loka Abaya (E2 and E3) would suggest relatively stable ranking of genotypes. The present study showed that genotypes Etsub, Simada and Tseday would be recommended for high yield and wide adaptation, and ASV would be used alone or jointly with YSI, $W_{i}$ and $\delta_{i}^{2}$ for ranking of genotypes.

\section{Acknowledgements}

The author thanks South Agricultural Research Institute, Hawassa, Ethiopia, for financial support, and Mr. Wondimagegn Amenu of Hawassa Agricultural Research Center, Hawassa, Ethiopia, for technical assistance, and Cereals Improvement Research staff of Areka Agricultural Research Center, Areka, Ethiopia, for handling of field experiments at Areka.

\section{Conflicts of Interest}

The author declares no conflicts of interest regarding the publication of this paper.

\section{References}

[1] CSA (2017) Agricultural Sample Survey: Report on Area and Production of Major Crops (Private Peasant Holdings, meher Season), 2016/2017 (2009 E.C.), Volume I, Statistical Bulletin 584. Central Statistical Agency (CSA), Addis Ababa.

[2] Yang, R.C. and Baker, R.J. (1991) Genotype-Environment Interactions in Two Wheat Crosses. Crop Science, 31, 83-87. https://doi.org/10.2135/cropsci1991.0011183X003100010021x

[3] Comstock, R.E. and Moll, R.H. (1963) Genotype x Environment Interactions. In: Symposium on Statistical Genetics and Plant Breeding, National Academy Science, National Research Council, Washington DC, 164-196.

[4] Becker, H.C. (1981) Correlations among Some Statistical Measures of Phenotypic Stability. Euphytica, 30, 835-840.

[5] Wricke, G. (1962) Uber eine methode zur erfassung der okologischen streubreite in feldversuchen. Z. Pflanzenzuecht, 47, 92-96.

[6] Shukla, G.K. (1972) Some Statistical Aspects of Partitioning Genotype-Environmental Components of Variability. Heredity, 29, 237-245.

[7] Lin, C.S. and Binns, M.R. (1988) A Superiority Measure of Cultivar Performance for Cultivar x Location Data. Canadian Journal of Plant Science, 68, 193-198. https://doi.org/10.4141/cjps88-018

[8] Snedecor, G.W. and Cochran, B.W. (1980) Statistical Methods. 7th Edition, Iowa State University, Ames.

[9] Zobel,R.W., Wright, M.J. and Gauch, H.G. (1988) Statistical Analysis of a Yield Trial. Agronomy Journal, 80, 388-393. https://doi.org/10.2134/agronj1988.00021962008000030002x

[10] Gauch, H.G. and Zobel, R.W. (1997) Identifying Mega-Environments and Targeting 
Genotypes. Crop Science, 37, 311-326.

https://doi.org/10.2135/cropsci1997.0011183X003700020002x

[11] Hongyu, K., Garcia-Pena, M., de Araujo, L.B. and Dias, C.T.S. (2014) Statistical Analysis of Yield Trials by AMMI Analysis of Genotype $\times$ Environment Interaction. Biometrical Letters, 51, 89-102. https://doi.org/10.2478/bile-2014-0007

[12] Neisse, A.C., Kirch, J.L. and Hongyu, K. (2018) AMMI and GGE Biplot for Genotype $\times$ Environment Interaction: A Medoid-Based Hierarchical Cluster Analysis Approach for High-Dimensional Data. Biometrical Letters, 55, 97-121. https://doi.org/10.2478/bile-2018-0008

[13] Lin, C.S., Binns, M.R. and Lefkovitch, L.P. (1986) Stability Analysis: Where Do We Stand? Crop Science, 26, 894-900. https://doi.org/10.2135/cropsci1986.0011183X002600050012x

[14] Purchase, J.L.,Hatting, H. and van Deventer, C.S. (2000) Genotype $\times$ Environment Interaction of Winter Wheat (Triticum aestivum L.) in South Africa: II. Stability Analysis of Yield Performance. South African Journal of Plant and Soil, 17, 101-107. https://doi.org/10.1080/02571862.2000.10634878

[15] SAS Institute (2002) SAS/STAT 9.0 User's Guide. SAS Institute, Cary.

[16] VSN International (2015) Genstat for Windows. 18th Edition, VSN International Ltd., Hemel Hempstead, UK.

[17] Yan, W. (2002) Singular-Value Partitioning in Biplot Analysis of Multienvironment Trial Data. Agronomy Journal, 94, 990-996. https://doi.org/10.2134/agronj2002.0990

[18] Gauch, H.G. (2006) Statistical Analysis of Yield Trials by AMMI and GGE. Crop Science, 46, 1488-1500. https://doi.org/10.2135/cropsci2005.07-0193

[19] Gauch, H.G. (1992) Statistical Analysis of Regional Yield Trials: AMMI Analysis of Factorial Designs. Elsevier, Amsterdam.

[20] Kang, M.S., Miller, J.D. and Darrah, L.L. (1987) A Note on Relationship between Stability Variance and Ecovalence. Journal of Heredity, 78, 107. https://doi.org/10.1093/oxfordjournals.jhered.a110322

[21] Gauch, H.G. (1988) Model Selection and Validation for Yield Trials with Interaction. Biometrics, 44, 705-715. https://doi.org/10.2307/2531585

[22] Bose, L.K., Jambhulkar, N.N., Pande, K. and Singh, O.N. (2014) Use of AMMI and other Stability Statistics in the Simultaneous Selection of Rice Genotypes for Yield and Stability under Direct-Seeded Conditions. Chilean Journal of Agricultural Research, 74, 1-9. https://doi.org/10.4067/S0718-58392014000100001

[23] Yan, W. and Tinker, N.A. (2006) Biplot Analysis of Multi-Environment Trial Data, Principles and Applications. Canadian Journal of Plant Science, 86, 623-645. https://doi.org/10.4141/P05-169 